F. Reprod. Fert. (1974) 41, 441-445

\title{
STUDIES ON THE EQUINE PLACENTA
}

\section{DEVELOPMENT OF THE MICROCOTYLEDONS}

\author{
GAROLE A. SAMUEL, W. R. ALLEN* AND D. H. STEVEN \\ Department of Anatomy, University of Cambridge, and \\ *Animal Research Station, Cambridge
}

(Received 3rd May 1974)

\begin{abstract}
Summary. By the 60th day of gestation, the microcotyledons of the equine placenta can be recognized as a simple folding of the trophoblast and adjacent uterine epithelium. Secondary folds are evident by Day 100 . By 150 days, further complex folding has resulted in the formation of mature multibranched villous structures each surrounded by a maternal connective tissue capsule.

There is no evidence to suggest that the microcotyledons are formed by a grouping of chorionic villi around the mouths of the uterine glands. Each microcotyledon develops from a number of primary folds which are related to small aglandular areas of the endometrium.
\end{abstract}

\section{INTRODUCTION}

Information on the development of the diffuse epitheliochorial placenta of the horse is fragmentary and widely scattered in the scientific literature. The later aspects of placental structure and organization have been described at various times by several different authors (Turner, 1876; Amoroso, 1952; Tsutsumi, 1962; Björkman, 1965, 1973) but a systematic study of placental development throughout pregnancy is still lacking. This paper describes the morphological changes which occur during formation of the microcotyledons of the horse placenta.

\section{MATERIALS AND METHODS}

The stage of gestation in five Welsh Mountain Pony mares was calculated from the time of ovulation (Day 0). Tissues were recovered at laparotomy between 61 and 150 days of pregnancy (Table 1). The animals were maintained under general anaesthesia and the uterus was exposed through a midventral incision in the abdominal wall. A $5 \mathrm{~cm}$ incision was made through the uterus and fetal membranes and both layers were immediately clamped together at each end of the incision to prevent excessive movement and maintain structural integrity. A 2-cm strip of uterus and placenta was then excised parallel to the original incision around the clamps and placed fetal-side downwards on a rectangle of rough-surfaced dry card. The myometrium was dissected

* Postal address: 307 Huntingdon Road, Cambridge GB3 0JQ. 
Table 1. Equine placentae examined in this survey

\begin{tabular}{c|c|c|l}
\hline Number & $\begin{array}{c}\text { Gestational } \\
\text { age (days) }\end{array}$ & $\begin{array}{c}\text { Crown-rump } \\
\text { length }(\mathrm{cm})\end{array}$ & $\begin{array}{c}\text { Sex of } \\
\text { fetus }\end{array}$ \\
\hline 1 & 61 & 8 & Male \\
2 & 98 & 17 & Male \\
3 & 101 & 20 & Male \\
4 & 150 & 34 & Male \\
5 & 150 & 34 & Female \\
\hline
\end{tabular}

free and the underlying placental tissue, together with the card, was then cut into pieces approximately $1 \mathrm{~cm}$ wide $\times 2 \mathrm{~cm}$ long $\times 2 \mathrm{~mm}$ thick and immersed for $90 \mathrm{~min}$ in a fixative consisting of $4 \%$ glutaraldehyde (Taab) variously buffered at $\mathrm{pH} 7.4$ with $0.1 \mathrm{M}$-phosphate; $0.1 \mathrm{~m}$-phosphate with $2 \%$ sucrose; $0.1 \mathrm{M}$-S-collidine or $0.15 \mathrm{M}$-sodium cacodylate. The fixed tissue was then separated from the card and cut into portions 1 to $2 \mathrm{~mm}$ wide. Post-fixation was carried out at room temperature $\left(22^{\circ} \mathrm{C}\right)$ in $1 \%$ osmium tetroxide in the same buffer used for the fixative. Dehydration in alcohols was followed by infiltration with 1,2-epoxypropane and Araldite (CIBA). Polymerization was carried out at $60^{\circ} \mathrm{C}$ for $48 \mathrm{hr}$.

Thick sections ( 1 to $2 \mu \mathrm{m}$ ) were stained with $1 \%$ methylene blue and $1 \%$ azure II (50:50) in $1 \%$ borax and examined under the light microscope. Ultra-thin sections were cut using glass knives on a Reichert Ultramicrotome and examined with a Philips 300 or AEI 6B electron microscope.

\section{EXPLANATION OF PLATES 1 TO 3}

Bars on light micrographs indicate $100 \mu \mathrm{m}$; bars on electron micrographs indicate $10 \mu \mathrm{m}$. Abbreviations: bl, basal lamina; coll, collagen; conn, connective tissue; ER, endoplasmic reticulum; FV, fetal vessel; IC, intercotyledonary areas; $L$, lipid inclusion; $m$, mitochondrion; mv, microvilli; $\mathrm{ME}$, maternal epithelium; $\mathrm{MV}$, maternal vessel; $\mathrm{N}$, nucleus; pv, pinocytotic vesicles; $T$, trophoblast.

\section{PLATE 1}

Fig. 1. Equine placenta at 61 days, showing simple apposition of the trophoblast and uterine epithelium. Vascularization of the chorion by the allantois has begun.

FIG. 2. Cross-section of an equine placental villus at 61 days. Fetal vessels are visible in the core of the villus. Lipid droplets are prominent in the maternal epithelium.

Fic. 3. Electron micrograph of an equine placenta at 61 days, showing the microvillous junction.

\section{PLATE 2}

FIG. 4. Equine placenta at 100 days, showing more complex folding of the junction.

Fig. 5. Equine placenta at 100 days, showing complexity of fetal connective tissue and reduction of maternal connective tissue.

Fig. 6. Electron micrograph of an equine placenta at 100 days. There is evidence of branching in the microvilli (arrow) and the maternal epithelium is greatly reduced in height. Collagen fibres separate the maternal vessel and epithelium, but the basal laminae are fused on the fetal side.

PLATE 3

Fig. 7. Equine placenta at 150 days. Folding of the junction has become very complex. A connective tissue capsule surrounds the maternal aspect of the microcotyledon (arrows). Fig. 8. Detail of the complex folding of the feto-maternal junction.

FIG. 9. Cross-section of a microcotyledon of an equine placenta, showing compression of maternal epithelium and blood vessels. 

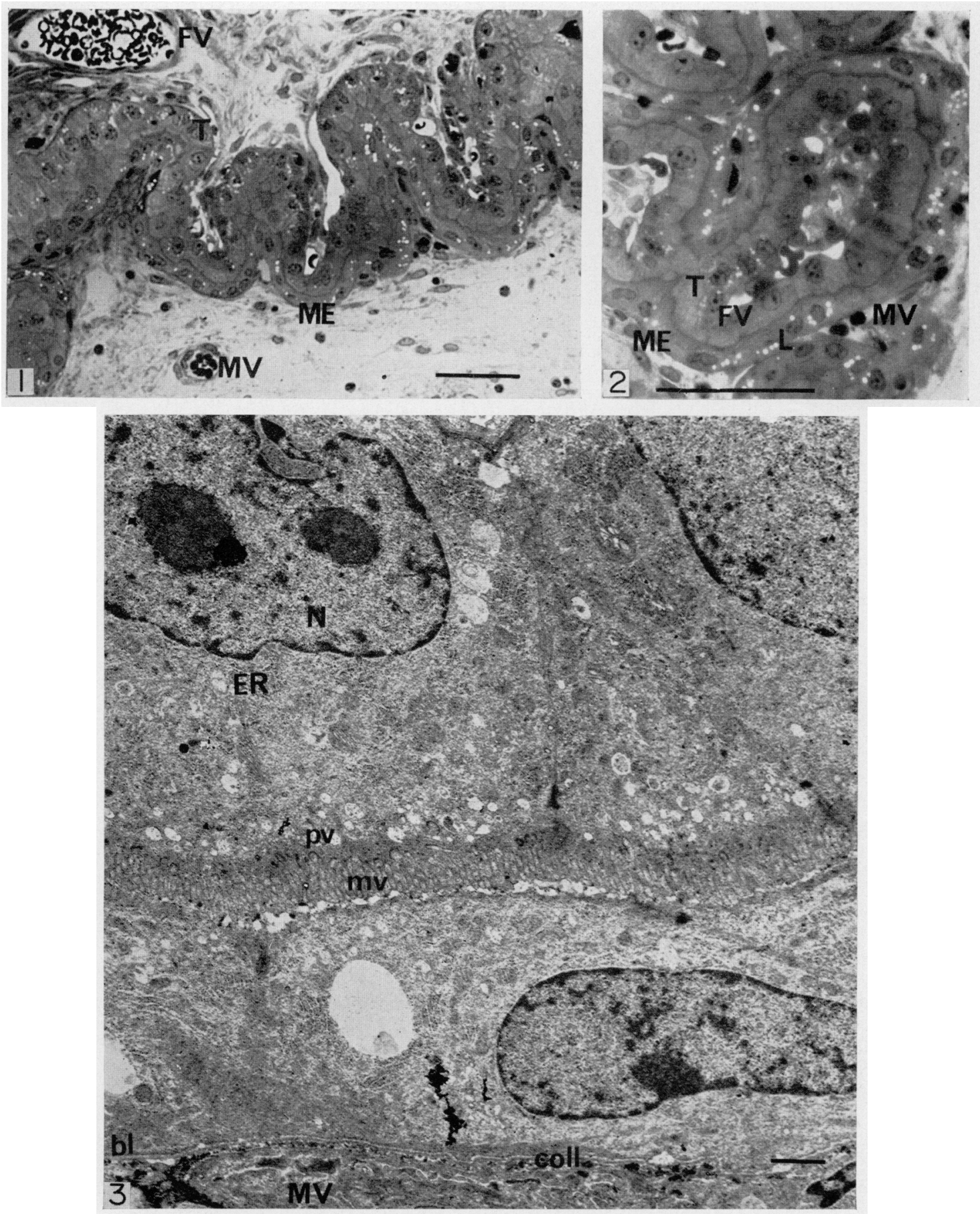

(Facilg) H. 12) 

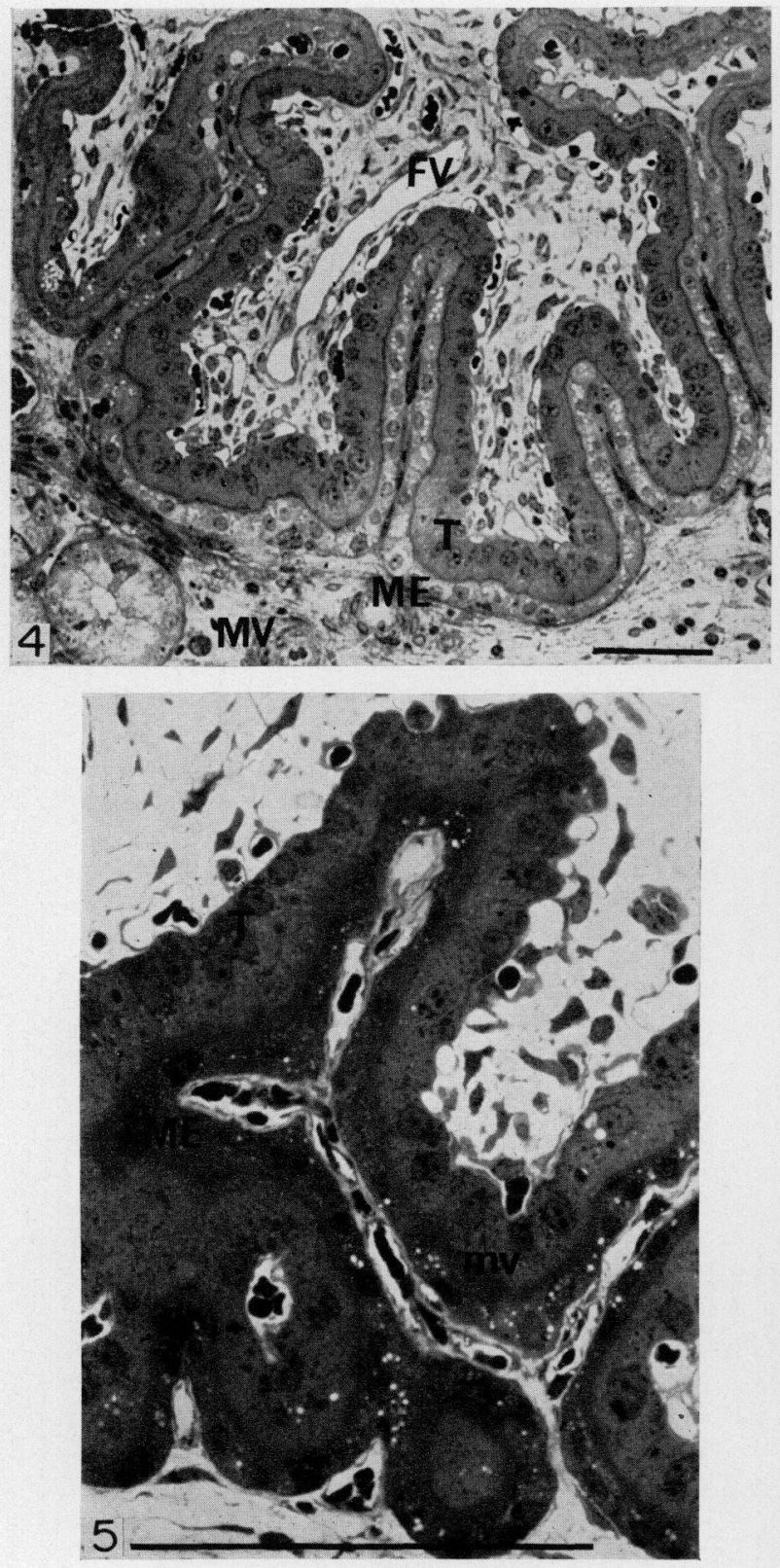

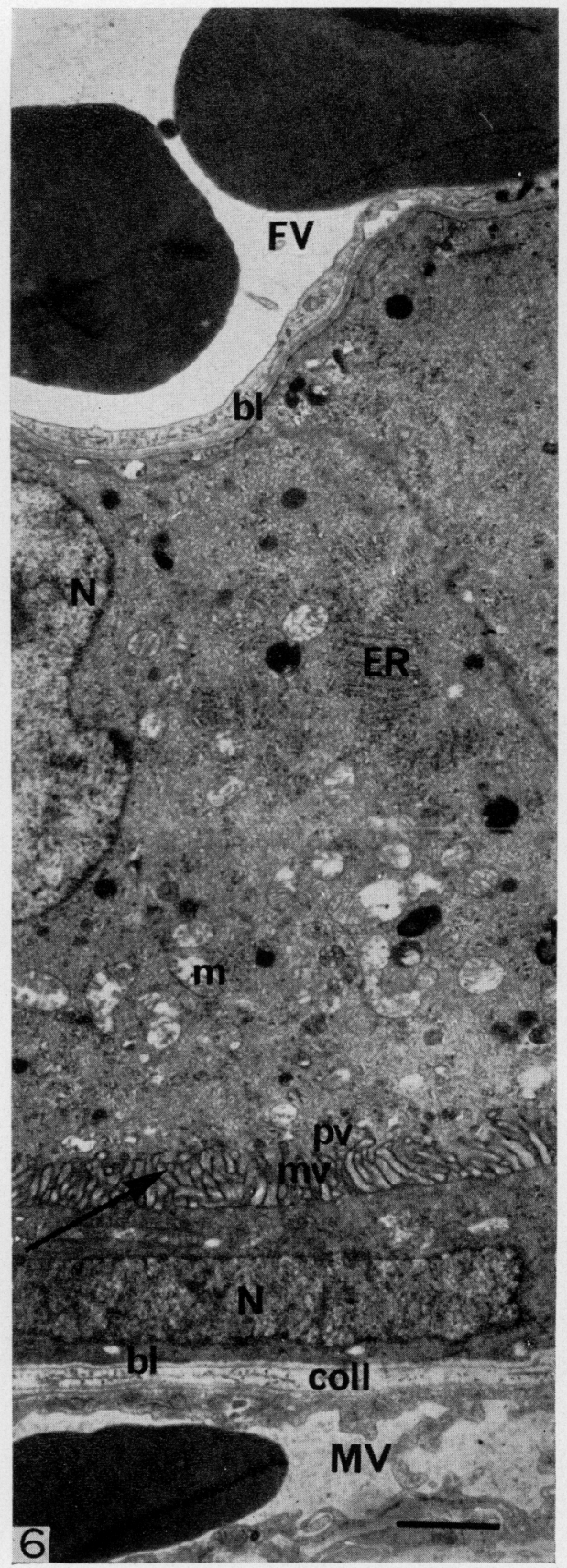


PLATE 3
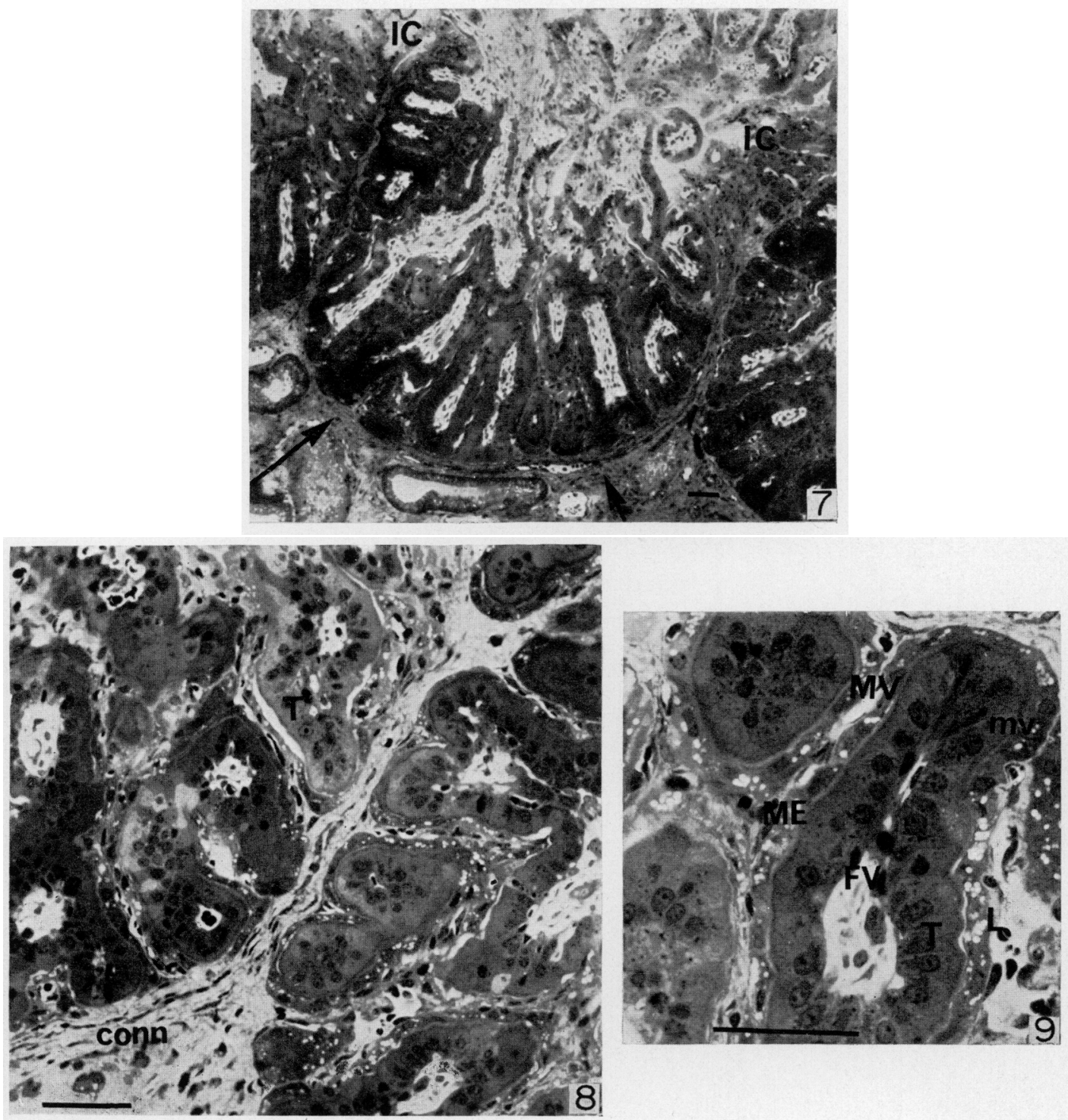


\section{RESULTS}

No single buffer system gave perfect results with all the placentae studied, although phosphate gave adequate fixation throughout. In some instances, the fetal tissue fixed well, but in others, the maternal tissues alone were well preserved. Phosphate buffer with added sucrose produced severe distortion of both fetal and maternal tissue, especially in the earlier stages of gestation.

At Day 61 of gestation, the trophoblast consisted of a single layer of tall columnar cells closely apposed to the uterine epithelium microvilli protruding from the luminal surface of the trophoblast interdigitated with those of the maternal epithelium (Pl. 1, Figs 1 to 3). The trophoblast cells contained large ovoid nuclei, small areas of rough endoplasmic reticulum and occasional lipid droplets. Small mitochondria and small vesicles were present in the apical portions of the cells and the Golgi apparatus was visible at this stage. The cells rested upon a basal lamina of varying thickness but uniform density which, in turn, was supported by a layer of collagen fibres.

The simple allantochorionic villi contained vessels and a core of connective tissue which consisted of fibrocytes and pericytes supported in a mesh of collagen fibres (Pl. 1, Fig. 3).

By Day 100 of pregnancy, the villous structure of the placental junction had become more complex with secondary folding of the primary villi (Pl. 2, Fig. 4). The trophoblast was cuboidal (Pl. 2, Fig. 5), largely as a result of stretching of the membranes due to expansion of the conceptus, and was reduced in height where fetal vessels were present. The microvillous attachment (PI. 2, Fig. 6) was similar to that at 61 days although there were signs of branching of the fetal microvilli. The trophoblast cells were still simple in structure with limited areas of organized endoplasmic reticulum and small mitochondria.

By Day 150, the microcotyledons were well developed (Pl. 3, Fig. 7) and the intricate folding of the feto-maternal junction was limited to discrete pockets of the uterine epithelium separated by smooth-surfaced intercotyledonary areas. The amount of fetal connective tissue had increased considerably and a connective tissue capsule had developed around the periphery of the microcotyledon on the maternal side. The trophoblast cells (Pl. 3, Fig. 8) had again become columnar. Many mitotic figures were visible. The maternal epithelium was greatly reduced in thickness (Pl. 3, Fig. 9) and contained numerous lipid droplets. Maternal blood vessels were visible in the septa between successive villous folds and the interdigitating microvilli at the feto-maternal junction had become longer and thinner.

\section{DISGUSSION}

No systematic examination of the stage of gestation at which the microcotyledons of the equine placenta first appear or of the sequential structural changes which occur at the feto-maternal junction during their development has been undertaken. Studies by Amoroso (1952), Tsutsumi (1962) and Björkman (1965) have been confined to the later stages of pregnancy. Our study has demonstrated that microcotyledons have already begun to develop by Day 60 of gestation, 

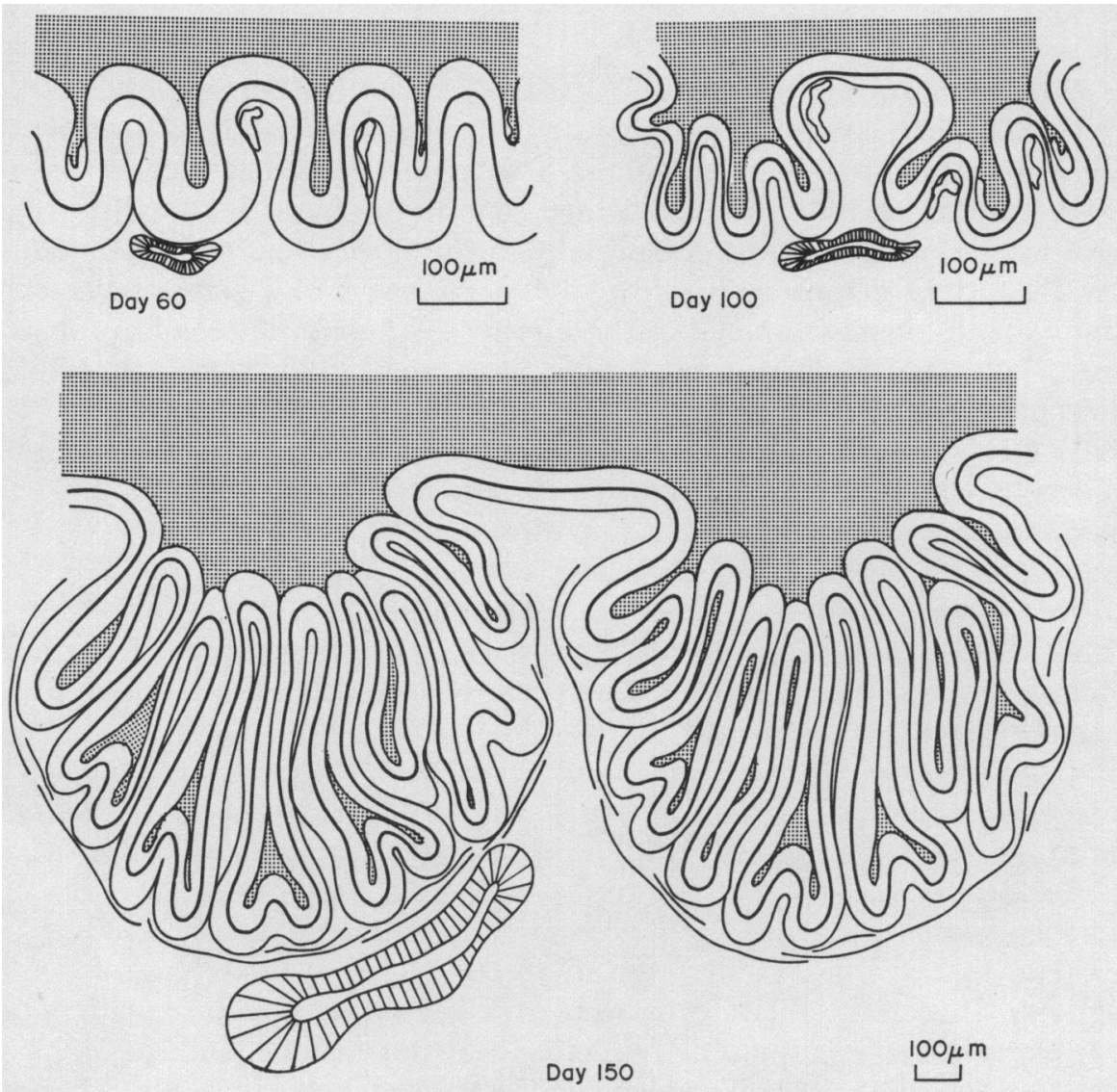

TEXT-FIG. 1. Diagrammatic representation of changes leading to the formation of the microcotyledons in the equine placenta.

when they are represented by a simple folding of the trophoblast and adjacent uterine epithelial layers. This folding process continues rapidly and welldeveloped secondary folds are evident by Day 100. Further complex folding takes place over the next 30 to 40 days until mature multi-branched cotyledons with a complete connective tissue capsule surrounding the maternal aspect are present by Day 150 .

Amoroso (1952) suggested that each microcotyledon develops from an individual villus which divides many times to give the final branching structure. Our observations do not support this theory. They indicate that a number of primary folds are involved in the process, with secondary folds being tightly compressed (see Text-fig. 1). The fetal side of the microcotyledon in the mature placenta was described by Amoroso (1952) as a villus with a main stem and many secondary branches. Our observations suggest that this fetal component forms from a number of primary folds, which together contribute to the formation of the main stem (see Text-fig. 1).

While complete attachment of the chorion to the endometrium may not occur over the whole of the conceptus until as late as 90 to 95 days of gestation 
(Amoroso, 1952), a continuous microvillous junction between trophoblast and uterine epithelium nevertheless exists in the central regions of the conceptus by Day 60. The microvillous attachment does not appear to be influenced by variations in shape of the trophoblast cells which chiefly occur at the proximal and distal extremities of the chorionic villi.

Development of the allantois commences in equids at the 21st day of gestation (Ewart, 1897) and the enlarging allantois has completely replaced the yolk-sac as a placental structure by Day 45 (Allen, 1970). Fusion of the allantois with the chorion gives rise to the true allantochorionic placenta. During the formation of the microcotyledons, the fetal capillaries begin to indent the chorionic epithelium from which they were previously separated by a layer of connective tissue. The basal laminae of capillaries and epithelium now fuse to form a single structure. At the same time, the maternal capillaries come to lie closer to the uterine epithelium although still separated by a thin layer of collagen fibres. These changes are concomitant with the formation of a connective tissue capsule around the microcotyledon which limits the space into which the fetal villi may expand.

\section{AGKNOWLEDGMENTS}

This work was supported by the Thoroughbred Breeders Association and the Medical and Agricultural Research Councils. We are most grateful to $\mathrm{Mr}$ L. E. A. Rowson, F.R.s., for assistance with the surgery; to the staff of the A.R.C. Unit of Reproductive Physiology and Biochemistry, and of the Department of Anatomy, University of Cambridge. One of us (C.A.S.) is a Medical Research Council Junior Research Fellow.

\section{REFERENCES}

AlLEN, W. R. (1970) Endocrinology of early pregnancy in the mare. Equine vet. F. 2, 66.

Amoroso, E. C. (1952) Placentation. In Marshall's Physiology of Reproduction, 3rd edn, Vol. 2, pp. 127311. Ed. A. S. Parkes. Longmans Green, London.

BJörkman, N. (1965) The fine morphology of the area of foetal maternal apposition in the equine placenta. Z. Zellforsch. mikrosk. Anat. 65, 285.

BJörкMAN, N. (1973) Fine structure of the fetal-maternal area of exchange in the epitheliochorial and endotheliochorial types of placentation. Acta anat. 86, 1.

Ewart, J. C. (1897) A Critical Period in the Development of the Horse. Adam \& Charles Black, Edinburgh.

Tsutsum, Y. (1962) The vascular patterns of the placenta in farm animals. F. Fae. Agr. Hokkaido (imp.) Univ. 52, 372.

Turner, W. M. (1876) Lectures on the Comparative Anatomy of the Placenta, pp. 38-42. Adam \& Charles Black, Edinburgh. 